\title{
Long-term almond supplementation without advice on food replacement induces favourable nutrient modifications to the habitual diets of free-living individuals*
}

\author{
Karen Jaceldo-Siegl ${ }^{1} \dagger$, Joan Sabaté ${ }^{1,2}$, Sujatha Rajaram ${ }^{1}$ and Gary E. Fraser ${ }^{2}$ \\ Departments of ${ }^{1}$ Nutrition, and ${ }^{2}$ Epidemiology and Biostatistics, School of Public Health, Loma Linda University, Loma \\ Linda, CA 92350, USA
}

(Received 14 April 2004 - Revised 7 May 2004 - Accepted 15 May 2004)

\begin{abstract}
Epidemiological and metabolic studies have shown that regular nut consumption may protect against risk of heart disease and diabetes. None has investigated the effect of adding nuts to a self-selected habitual diet (containing little or no nuts) on dietary patterns. The present study evaluated the impact of long-term almond supplementation in healthy men $(n$ 43) and women $(n$ 38) aged 25-70 years on nutrient profile and nutrient displacement. All subjects were followed for 1 year. During the first 6 months, subjects followed their habitual diets; in the second 6 months, subjects added almonds to their diets. Diets were assessed by seven random $24 \mathrm{~h}$ telephone diet recalls during each diet period. On average, the almond supplement was $52 \mathrm{~g} / \mathrm{d}$ (about forty-two nuts) containing $1286 \mathrm{~kJ}$. When subjects changed from their habitual diet to the almond-supplemented diet, the intakes of MUFA, PUFA, fibre, vegetable protein, $\alpha$-tocopherol, $\mathrm{Cu}$ and $\mathrm{Mg}$ significantly $(P<0.05)$ increased by $42,24,12,19,66,15$ and $23 \%$ respectively; the intakes of trans fatty acids, animal protein, Na, cholesterol and sugars significantly $(P<0.05)$ decreased by $14,9,21,17$ and $13 \%$ respectively. These spontaneous nutrient changes closely match the dietary recommendations to prevent cardiovascular and other chronic diseases. Displacement estimates for total energy, total protein, total fat, SFA, MUFA, PUFA, total fibre, $\mathrm{Ca}, \mathrm{Fe}, \mathrm{Mg}, \mathrm{P}, \mathrm{K}, \mathrm{Zn}$ and $\alpha$-tocopherol ranged from 16 to $98 \%$; the estimates for total food weight, carbohydrate, sugars and Se were $>245 \%$. A daily supplement of almonds can induce favourable nutrient modifications for chronic disease prevention to an individual's habitual diet.
\end{abstract}

Almonds: Habitutal diets: Nutrient intake: Nutrient displacement

The association between habitual dietary patterns and health status is well recognized (Appel et al. 1997; Fung et al. 2001; Lauber \& Sheard, 2001). Scientific knowledge on the role of diet in health has prompted organizations such as the World Health Organization, few nutrition councils from Europe, the Food and Nutrition Board and other authorities to issue dietary recommendations or guidelines for the public to promote healthful eating and prevent disease (Food and Nutrition Board, National Research Council, 1989; World Health Organization, 1990; Norum et al. 1997; Serra-Majem et al. 1997; Haddad, 2001). Some guidelines provide information about the consumption of foods and types of foods that can help the public make healthy choices. Food groups such as grains, fruits, vegetables, dairy products and meats have been incorporated into these recommendations. Because of the growing evidence of the cardio-protective effect of nuts, examining the potential of nuts as a healthy food choice would be timely.

Findings from large epidemiological investigations (Fraser et al. 1992; Prineas et al. 1993; Hu et al. 1998; Albert et al. 2002; Jiang et al. 2002) and several metabolic studies (Kris-Etherton et al. 1999; Sabate et al. 2001) have shown that regular nut consumption may protect against the risks of heart disease and diabetes. Specifically, the focus of nut research to date has been on the beneficial effect of nut consumption on plasma lipoproteins, plasma fatty acids (Sabate \& Fraser, 1993; Kris-Etherton et al. 1999; Curb et al. 2000; Almario et al. 2001; Rajaram et al. 2001; Jenkins et al. 2003; Sabate et al. 2003), and more recently, body weight (McManus et al. 2001; Wien et al. 2003). In a previous publication we reported a small weight gain $(0.4 \mathrm{~kg}$, compatible with chance) after almond supplementation for 6 months (Fraser et al. 2002). The aforementioned studies, with the exception of those that evaluated body weight, have been short-term feeding studies that used rigorous dietary intervention, which not only introduced nuts into the diet as the primary variable, but also imposed a prescribed reference diet that departed from each individual's habitual diet.

In the present study the effect of a daily supplement of nuts on the overall habitual diets of healthy subjects was examined. The impact of almond supplementation on nutrient profile and nutrient displacement of almond-supplemented

\footnotetext{
*This paper was presented in part at the International Congress of Nutrition, Vienna, Austria, August 2001.

$\dagger$ Corresponding author: Dr Karen Jaceldo-Siegl, fax +1909 558 0419, email kjaceldo@sph.llu.edu
} 
habitual diets will be reported and discussed in the present paper.

\section{Methods}

\section{Subjects}

Subjects were recruited by newspaper, radio and bulletin board announcements. Men and women aged 25-70 years who met the inclusion criterion were enrolled. Individuals successfully enrolled in the study were below the 95th percentile of their age- and gender-specific BMI distribution (Must et al. 1991), did not have $>9 \mathrm{~kg}$ weight change during the previous 6 months, ate nuts less than twice per week or ate $<7 \mathrm{~g}$ nuts per week, did not smoke, had no allergy or aversion to nuts, did not follow a rigorous exercise programme, had no concurrent medical conditions that might affect body weight, drank no more than two glasses of alcoholic beverage per d, were not pregnant, or did not consume a very atypical diet.

\section{Design}

Details of the randomization strategy used to enrol subjects into the present study have been reported previously (Fraser et al. 2002). Briefly, subjects were entered into the study at staggered 3-month intervals, each period representing a particular season of the year to offset any seasonal effects on diet. Subjects were randomly allocated to each of these four entry periods stratified by age, gender and BMI. In each quarter, equal numbers of subjects, with similar attributes, were enrolled.

All subjects were followed for 12 months. The first 6 months was the control diet period, where all subjects followed their habitual self-selected diet. Although there was no intervention during the habitual diet period, the diets were assessed. The intervention occurred during the second 6 months, which required subjects to consume a daily allowance of almonds; this period will be referred to as the almond-supplemented diet period. The almond supplement was equivalent to $15 \%$ of each subject's mean energy intake during the habitual diet period. Individuals whose energy intake was in the lowest tertile received $42 \mathrm{~g}$, middle tertile $57 \mathrm{~g}$ and the highest tertile $71 \mathrm{~g}$. Subjects had a choice of dry roasted or raw nuts, or both. All subjects were provided packaged daily portions of the almond supplement, labelled with a particular day of the week and the weight (ounces). No dietary advice was given, except to suggest simply that the almonds may be eaten with meals or as snacks, or added to desserts or salads.

\section{Dietary assessment}

Dietary recalls $(24 \mathrm{~h})$. During each 6-month diet period, seven (one on each day of the week) random-order telephone $24 \mathrm{~h}$ diet recalls were obtained by trained dietitians using Nutrition Data System (NDS) software package (version 2.8, 1993; The Nutrition Coordinating Center, University of Minnesota, Minneapolis, MN, USA). Dietary recalls were unannounced and collected at 3-week intervals.
Nutrient calculations were performed using NDS-R Food and Nutrient Database 34, released May 2003 (Schakel et al. 1988).

Food diaries. During the second month of the habitual diet period, subjects were given a $1 \mathrm{~d}$ (practice) food diary to record their food intakes. The diary was a booklet containing detailed instructions and photographs of different servings of foods. Subjects were asked to record in detail every item that they ate or drank. After completion of the $1 \mathrm{~d}$ practice diary, a nutritionist reviewed the diary, and subjects were instructed if any recording errors were noted. For each diet period, two food diaries (one Sunday and one Wednesday) were subsequently obtained. Diaries were collected at months 4 and 6 during the habitual diet period, and at months 8 and 12 during the intervention period. After the completed diaries were submitted, one of the authors (K. J.-S.) reviewed the diaries and contacted the subjects by phone when data needed clarification. Food diary data were entered using the Nutrition Data System.

\section{Compliance}

Compliance was assessed by examining the congruence between the dietary recalls and food diaries in the reported amount of almonds consumed. Other methods of compliance were reported and discussed previously (Fraser et al. 2002).

\section{Estimation of nutrient displacement}

Let $i$ be a nutrient. $\mathrm{H}_{i}$ is the intake of a nutrient during the habitual diet; $S_{i}$ is the amount of that nutrient contained in the almond supplement; $A_{i}$ is the intake of that nutrient during the almond-supplemented diet period. Since the almond supplement was added to the habitual diet, the expected intake of that nutrient in the supplemented diet is $\mathrm{H}_{i}+\mathrm{S}_{i}$. Displacement of that nutrient $\left(\mathrm{D}_{i}\right)$ was estimated by subtracting the observed intake of that nutrient in the supplemented diet, $\mathrm{A}_{i}$, from the expected intake of that nutrient. Thus, $\mathrm{D}_{i}=\left(\mathrm{H}_{i}+\mathrm{S}_{i}\right)-\mathrm{A}_{i}$. Percentage displacement was calculated by $\mathrm{D}_{i} / \mathrm{S}_{i} \times 100$.

\section{Statistical analysis}

The arithmetic mean value of the seven diet recalls from each diet period was calculated, and a paired $t$ test was used to compare results from the habitual and almond-supplemented diet periods. In view of the instability of the mean value as a measure of central tendency when distributions are skewed, we used the median value to report the ratio variable percentage difference. The null hypothesis that this equals zero was tested using the binomial sign test (Sheskin, 2000). Statistical significance was defined by $P=0.05$ (two-sided). Results are presented as mean values and standard deviations or as mean values with their standard errors. Analyses were conducted using Statistical Analysis System for Windows statistical software package, version 8 (SAS Institute Inc., Cary, NC, USA, 1999). 


\section{Ethical approval}

Approval of the design and ethical conduct of the present study was obtained from the Institutional Review Board of The Loma Linda University Human Subjects Committee before the study began. Subjects gave written consent to participate and received US $\$ 100$ for successful participation in the study.

\section{Results}

\section{Subjects}

Initially 100 subjects were enrolled and eighty-one completed the study. Thirteen women and six men dropped out. The average age of the subjects who dropped out was 40.4 years. Among those who completed the study, $83 \%$ were white, $2 \%$ black, $6 \%$ Asian and $7 \%$ other. Vitamin supplements were used by $64 \%$ of subjects during the habitual diet period and by $56 \%$ during the almond-supplemented diet period. Selected baseline characteristics of these subjects are shown in Table 1. The average age of individuals who completed the study was 49.2 years for males and 49.9 years for females. Gender differences in BMI values were similar to those observed in the US population (Must et al. 1991).

\section{Compliance}

During the almond-supplemented diet period, 567 diet recalls $(24 \mathrm{~h})$ were obtained and 167 single food diaries were collected from subjects. Almonds were reported as eaten in $90.2 \%$ of the recalls and $89.2 \%$ of the diaries.

\section{Nutrient profile}

Since there were no significant gender differences in the intake of macronutrients and minerals, data for male and female subjects were combined in succeeding analyses.

Changes in the intake of selected macronutrients and dietary fatty acids when subjects changed from the habitual to the almond-supplemented diets are shown in Table 2 . Average total energy intake increased significantly $(P<0.01)$, but the total weight of food significantly decreased $(P<0.05)$. On average, the diets during the almond-supplemented diet period had higher total fibre content $(P<0.001)$ and insoluble:soluble fibre ratio $(P<0.0001)$ compared with the habitual diet. The average intakes of carbohydrate $(P<0.0001)$, sugars $(P<0.0001)$ and dietary cholesterol $(P<0.01)$ were significantly

Table 1. Baseline characteristics of subjects completing the study

(Mean values with their standard errors)

\begin{tabular}{lccccc}
\hline & \multicolumn{2}{c}{ Male } & & \multicolumn{2}{c}{ Female } \\
\cline { 2 - 3 } & Mean & SE & & Mean & SE \\
\hline Subjects $(n)$ & 43 & & & 38 & \\
Age (years) & 49.2 & 13.6 & & 49.9 & 13.4 \\
BMl $\left(\mathrm{kg} / \mathrm{m}^{2}\right)$ & 26.7 & 3.56 & & 25.9 & 5.54 \\
\hline
\end{tabular}

reduced during the almond-supplemented diet period by 11,13 and $17 \%$ respectively. Although total protein content did not change, protein intake from animal sources decreased $(P<0.0001)$ and protein from vegetable sources $(P<0.0001)$ rose significantly during the almond-supplemented diet period. The average lysine:arginine ratio increased significantly $(P<0 \cdot 0001)$ during the almond-supplemented diet period. Total fat intake increased by $20 \%$ during the almond-supplemented diet period $(P<0.0001)$, but there was a significant improvement in the fatty acid intake profile. During the almond-supplemented diet period, the intake of total SFA decreased by $3 \%$; MUFA and PUFA increased by 42 and $24 \%$ respectively. Specifically, dietary levels of stearic acid fell by $7 \%$, trans fatty acids decreased by $14 \%$, linoleic acid increased by $27 \%$ and oleic acid increased by $45 \%$ during the almond-supplemented diet period.

Changes in the relative intakes of micronutrients comparing the habitual and almond-supplemented diets are shown in Table 3. The intakes of $\mathrm{Mg}(P<0.0001)$ and $\mathrm{Cu}(P<0.0001)$ were significantly higher and Se significantly lower $(P<0.0001)$ during the almond-supplemented diet period compared with the habitual diet period. $\mathrm{Na}$ intake dropped significantly $(P<0.0001)$ by $21 \%$ during the almond-supplemented diet period. The intakes of $\mathrm{Ca}$, $\mathrm{Fe}, \mathrm{P}, \mathrm{K}$ and $\mathrm{Zn}$ did not change significantly. The intake of $\alpha$-tocopherol increased significantly $(P<0 \cdot 001) ; \beta$-carotene, thiamine, pantothenic acid and folic acid decreased significantly $(P<0 \cdot 05)$. There were no significant changes for the other vitamins.

\section{Nutrient displacement}

Estimates of percentage displacement of macro- and micronutrients and dietary fatty acids after 6-months supplementation with almonds are shown in Table 4 . The nutrient composition of the almond supplement is presented on the third column of Table 4, which reflects the mean values of the actual amount of almonds consumed by the subjects. On average, the almond supplement consumed by study participants was $52 \mathrm{~g}$. Based on our calculations, \% nutrient displacement by definition is an inverse measure of the degree to which the almond supplement induced a change in the content of a particular nutrient in the supplemented diet. For example, $0 \%$ displacement means that the amount of a nutrient $i$ present in almonds is totally added to the supplemented diet. Displacement estimates of $100 \%$ mean that nutrient $i$ from almonds replaced an equal amount of that nutrient in the supplemented diet by reducing the intake of nutrient $i$ from foods other than almonds. A value between 0 and 100 , therefore, indicates partial displacement. A value $>100 \%$ means nutrient $i$ in almonds more than fully displaced that nutrient, and the overall supplemented diet now contains less of this nutrient. A negative percentage displacement indicates that not only was there no displacement but that non-almond foods in the supplemented diet contained more of nutrient $i$ than in the habitual diet period.

In the almond-supplemented diet, more than one-half of the total energy, one-third of the protein and one-quarter of the fat present in almonds were displaced. Displaced dietary fatty acids in the almond-supplemented diet were 
Table 2. Changes in the intake of selected nutrients of eighty-one subjects assessed by seven $24 \mathrm{~h}$ recalls for each diet period $\dagger$ (Mean values and standard deviations)

\begin{tabular}{|c|c|c|c|c|c|c|c|c|}
\hline \multirow[b]{3}{*}{ Variable } & \multicolumn{4}{|c|}{ Dietary intake } & \multicolumn{4}{|c|}{ Difference } \\
\hline & \multicolumn{2}{|c|}{ Habitual diet (h) } & \multicolumn{2}{|c|}{$\begin{array}{l}\text { Almond-sup- } \\
\text { plemented diet (a) }\end{array}$} & \multicolumn{2}{|c|}{ Absolute $(a-h)$} & \multicolumn{2}{|c|}{$\%((a-h) / h \times 100)$} \\
\hline & Mean & SD & Mean & SD & Mean & SEM & Median & $P \neq$ \\
\hline Total food weight $(\mathrm{g} / \mathrm{d})$ & $3204 \cdot 2$ & 795.7 & 3074.9 & 729.6 & $-129 \cdot 2^{\star \star}$ & $46 \cdot 11$ & $-4 \cdot 6$ & 0.0140 \\
\hline Total energy $(\mathrm{kJ} / \mathrm{d})$ & $8528 \cdot 6$ & 2653.0 & $9116 \cdot 9$ & $2580 \cdot 7$ & $588 \cdot 3^{\star \star *}$ & $170 \cdot 42$ & $7 \cdot 7$ & 0.0036 \\
\hline Total protein (\% energy) & $14 \cdot 8$ & 2.9 & $15 \cdot 1$ & 2.9 & 0.4 & 0.26 & 1.4 & 0.6570 \\
\hline Animal protein (\% energy) & 8.5 & 3.2 & 7.6 & $2 \cdot 8$ & $-1 \cdot 0^{\star * \star *}$ & 0.23 & -9.4 & $<0.0001$ \\
\hline Vegetable protein ( $\%$ energy) & $6 \cdot 1$ & $2 \cdot \overline{3}$ & 7.5 & $2 \cdot 9$ & $1 \cdot 4^{\star \star \star \star}$ & 0.18 & 18.9 & $<0.0001$ \\
\hline Total fat (\% energy) & $32 \cdot 1$ & $6 \cdot 0$ & 38.5 & $5 \cdot 3$ & $6 \cdot 3^{\star \star \star *}$ & 0.49 & $20 \cdot 0$ & $<0.0001$ \\
\hline Total carbohydrate (\% energy) & 54.7 & 7.5 & $48 \cdot 6$ & $6 \cdot 9$ & $-6 \cdot 1^{\star \star \star *}$ & 0.52 & $-10 \cdot 8$ & $<0.0001$ \\
\hline Total fibre $(\mathrm{g} / 4184 \mathrm{~kJ})$ & $11 \cdot 2$ & $3 \cdot 2$ & 12.4 & 2.9 & $1 \cdot 2^{\star \star \star \star}$ & 0.27 & 11.8 & 0.0003 \\
\hline Soluble fibre (g/4184 kJ) & 3.9 & $1 \cdot 2$ & 3.6 & $1 \cdot 1$ & $-0.3^{\star \star}$ & $0 \cdot 11$ & $-7 \cdot 1$ & 0.0140 \\
\hline Insoluble fibre (g/4184 kJ) & $7 \cdot 3$ & $2 \cdot 1$ & $8 \cdot 6$ & 1.9 & $1 \cdot 3^{\star \star \star \star}$ & $0 \cdot 18$ & 16.5 & $<0.0001$ \\
\hline Insoluble:soluble fibre ratio & 1.9 & 0.3 & 2.5 & 0.4 & $0.6^{\star \star \star \star}$ & 0.05 & $\|$ & - \\
\hline Cholesterol (g/4184 kJ) & $105 \cdot 7$ & $49 \cdot 6$ & $88 \cdot 6$ & $39 \cdot 1$ & $-17 \cdot 1^{\star \star \star \star}$ & 3.89 & -16.5 & 0.0017 \\
\hline Sugars $(g / d)$ & $61 \cdot 7$ & $15 \cdot 4$ & 53.1 & $15 \cdot 6$ & $-8 \cdot 6^{\star \star \star *}$ & 1.20 & -12.9 & $<0.0001$ \\
\hline Water $(\mathrm{g} / \mathrm{d}) \S$ & 2757.4 & 723.2 & 2614.1 & $667 \cdot 6$ & $-143 \cdot 3^{\star \star}$ & 43.37 & -5.5 & 0.0073 \\
\hline Lys:Arg ratio & 0.85 & 0.11 & 1.07 & 0.14 & $0.22^{\star \star \star \star}$ & 0.01 & $\|$ & - \\
\hline \multicolumn{9}{|l|}{ Fatty acids } \\
\hline SFA (\% energy) & $10 \cdot 4$ & 2.5 & $9 \cdot 8$ & $2 \cdot 2$ & $-0.6^{\star \star}$ & 0.19 & -3.4 & 0.1193 \\
\hline MUFA (\% energy) & 11.8 & 2.5 & $17 \cdot 1$ & 2.4 & $5 \cdot 3^{\star \star \star \star}$ & 0.26 & 41.7 & $<0.0001$ \\
\hline PUFA (\% energy) & 7.5 & 1.9 & 9.0 & $1 \cdot 8$ & $1.5^{\star \star \star \star}$ & 0.19 & 23.9 & $<0.0001$ \\
\hline $16: 0$ (\% energy) & $5 \cdot 6$ & $1 \cdot 2$ & $5 \cdot 5$ & $1 \cdot 1$ & -0.1 & 0.08 & -0.8 & 0.6570 \\
\hline $18: 0$ (\% energy) & $2 \cdot 6$ & 0.7 & 2.4 & 0.6 & $-0.2^{\star \star \star *}$ & 0.06 & $-7 \cdot 2$ & 0.0140 \\
\hline $16: 1 n-7$ (\% energy) & 0.5 & 0.2 & 0.5 & 0.2 & 0.0 & 0.01 & 1.0 & 0.9999 \\
\hline $18: 1 n-9$ (\% energy) & $11 \cdot 1$ & 2.4 & $16 \cdot 5$ & $2 \cdot 3$ & $5 \cdot 4^{\star \star \star \star}$ & 0.26 & $45 \cdot 3$ & $<0.0001$ \\
\hline $18: 2 n-6$ (\% energy) & $6 \cdot 7$ & 1.8 & 8.2 & 1.6 & $1 \cdot 6^{\star \star \star \star}$ & 0.17 & $27 \cdot 2$ & $<0.0001$ \\
\hline $18: 3 n-3$ (\% energy) & 0.7 & 0.2 & $0 . \overline{6}$ & 0.2 & $-0 \cdot 1^{\star \star \star}$ & 0.03 & $-13 . \overline{5}$ & $<0.0001$ \\
\hline trans Fatty acid (\% energy) & 1.8 & 0.7 & 1.6 & 0.7 & $-0.2^{\star \star}$ & 0.07 & $-13 \cdot 8$ & 0.0140 \\
\hline
\end{tabular}

${ }^{* *} P<0.01,{ }^{* * *} P<0.001,{ }^{* * * *} P<0.0001$ ( $t$ test).

†For details of subjects, diets and procedures, see Table 1 and p. 534

$\ddagger$ Binomial sign test used to test the null hypothesis that the median $=0$

$\S$ Including all fluids.

|| Percentage differences for ratios not calculated.

$98 \%$ SFA, $16 \%$ MUFA and $26 \%$ PUFA found in almonds. The estimated displacements in the almond-supplemented diet for carbohydrate and sugars were 246 and $626 \%$ respectively. Nearly one-third of the total fibre content from almonds was displaced in the almond-supplemented diet.

Displacement estimates for $\mathrm{Ca}, \mathrm{Fe}, \mathrm{Mg}, \mathrm{P}, \mathrm{K}, \mathrm{Zn}$, $\alpha$-tocopherol, $\beta$-tocopherol and $\delta$-tocopherol ranged from 11 to $92 \%$ in the almond-supplemented diet. The micronutrients with displacement estimates of $\geq 100 \%$ were Se, riboflavin, pantothenic acid, pyridoxine, folic acid and $\gamma$-tocopherol. Micronutrients with negative displacement estimates in the almond-supplemented diet were $\mathrm{Cu}$, thiamine and niacin.

\section{Discussion}

Our present results indicate that simply prescribing a daily supplement of almonds ( $52 \mathrm{~g}$ ) can induce favourable nutrient modifications to an individual's habitual diet. The nutrient profile of the almond-supplemented diet was an overall improvement of the habitual diet: significant increases in the intake of MUFA, PUFA, plant protein, fibre, $\mathrm{Mg}, \mathrm{Cu}$ and $\alpha$-tocopherol, and significant reductions in trans fatty acid, animal protein, cholesterol, $\mathrm{Na}$ and sugars. These nutrients, along with others that decreased from the habitual to the almond-supplemented diet (Se, $\beta$-carotene, thiamine, pantothenic acid and folic acid), as well as those that remained relatively unchanged $(\mathrm{Ca}, \mathrm{Fe}$, $\mathrm{P}, \mathrm{K}, \mathrm{Zn}$ and other vitamins), largely met the dietary recommendations to prevent CVD and chronic diseases, or were consistent with the daily reference intakes (for summary, see Table 5) (Food and Nutrition Board, Institute of Medicine, 2000).

The fibre content of the almond-supplemented diet was within dietary recommendations, and well above the population average. Although the insoluble:soluble fibre ratio of the almond-supplemented diet was just below the dietary guidelines for chronic disease prevention (3:1), it was a significant improvement on the habitual diet. The cholesterol intake in the almond-supplemented diet (absolute cholesterol intake $191.1 \mathrm{mg} / \mathrm{d}$ ) was not only within the guidelines for the general population $(\leq 300 \mathrm{mg} / \mathrm{d})$, but also within recommendations for those at increased risk of developing CVD $(\leq 200 \mathrm{mg} / \mathrm{d}$ for individuals with diabetes, lipoprotein disorders or pre-existing heart disease) (Lauber \& Sheard, 2001).

In spite of the increased total fat intake in the almondsupplemented diet, changes in the dietary fatty acid profile were favourable, as was previously observed 
Table 3. Changes in the intake of selected nutrients of eighty-one subjects assessed by seven $24 \mathrm{~h}$ recalls for each diet period $\dagger$ (Mean values and standard deviations)

\begin{tabular}{|c|c|c|c|c|c|c|c|c|}
\hline \multirow[b]{3}{*}{ Variable } & \multicolumn{4}{|c|}{ Dietary intake } & \multicolumn{4}{|c|}{ Difference } \\
\hline & \multicolumn{2}{|c|}{ Habitual diet (h) } & \multicolumn{2}{|c|}{$\begin{array}{c}\text { Almond-sup- } \\
\text { plemented diet (a) }\end{array}$} & \multicolumn{2}{|c|}{ Absolute $(a-h)$} & \multicolumn{2}{|c|}{$\%((a-h) / h \times 100)$} \\
\hline & Mean & SD & Mean & SD & Mean & SEM & Median & $P \neq$ \\
\hline \multicolumn{9}{|l|}{ Minerals } \\
\hline $\mathrm{Ca}(\mathrm{mg} / 4184 \mathrm{~kJ})^{\star}$ & 569.9 & 241.4 & 543.1 & $208 \cdot 3$ & $-26 \cdot 8$ & $19 \cdot 77$ & -0.4 & 0.8243 \\
\hline $\mathrm{Fe}(\mathrm{mg} / 4184 \mathrm{~kJ})$ & 14.9 & $32 \cdot 8$ & $13 \cdot 3$ & 19.5 & -1.6 & 1.54 & -1.4 & 0.6570 \\
\hline $\mathrm{Mg}(\mathrm{mg} / 4184 \mathrm{~kJ})$ & 199.8 & 80.7 & 240.9 & $75 \cdot 1$ & $41 \cdot 1^{\star \star \star *}$ & $6 \cdot 21$ & $22 \cdot 8$ & $<0.0001$ \\
\hline $\mathrm{P}(\mathrm{mg} / 4184 \mathrm{~kJ})$ & $656 \cdot 7$ & $132 \cdot 7$ & $677 \cdot 8$ & $108 \cdot 1$ & $21 \cdot 1$ & $11 \cdot 30$ & 3.9 & 0.1821 \\
\hline $\mathrm{K}(\mathrm{mg} / 4184 \mathrm{~kJ})$ & $1519 \cdot 5$ & $326 \cdot 9$ & $1490 \cdot 7$ & 298.4 & $-28 \cdot 8$ & 29.94 & $-2 \cdot 0$ & 0.9999 \\
\hline $\mathrm{Na}(\mathrm{mg} / 4184 \mathrm{~kJ})$ & $1546 \cdot 4$ & $281 \cdot 1$ & $1209 \cdot 4$ & 319.4 & $-337 \cdot 0^{\star \star \star \star}$ & $40 \cdot 63$ & $-21 \cdot 0$ & $<0.0001$ \\
\hline $\mathrm{Zn}(\mathrm{mg} / 4184 \mathrm{~kJ})$ & 8.6 & $6 \cdot 8$ & 8.7 & 6.0 & 0.1 & 0.56 & 3.2 & 0.1821 \\
\hline $\mathrm{Cu}(\mathrm{mg} / 4184 \mathrm{~kJ})$ & 1.2 & 0.8 & 1.9 & 4.9 & 0.7 & 0.53 & 14.8 & $<0.0001$ \\
\hline $\mathrm{Se}(\mathrm{mg} / 4184 \mathrm{~kJ})$ & $67 \cdot \overline{6}$ & 38.3 & 57.9 & $37 \cdot 1$ & $-9 \cdot 8^{\star \star \star}$ & 2.63 & -12.5 & $<0.0001$ \\
\hline $\mathrm{Na}: \mathrm{K}$ ratio & 1.06 & 0.26 & 0.84 & 0.26 & $-0 \cdot 21^{\star \star \star \star}$ & 0.03 & $\S$ & - \\
\hline \multicolumn{9}{|l|}{ Vitamins } \\
\hline Vitamin A ( $\mu \mathrm{g} / 4184 \mathrm{~kJ})$ & $1199 \cdot 0$ & $1343 \cdot 8$ & $1031 \cdot 1$ & 921.9 & $-167 \cdot 9^{\star}$ & 88.23 & $-14 \cdot 6$ & 0.0448 \\
\hline$\beta$-Carotene $(\mu \mathrm{g} / 4184 \mathrm{~kJ})$ & 2439.0 & $1843 \cdot 3$ & $2067 \cdot 4$ & $1697 \cdot 0$ & $-371 \cdot 5^{\star}$ & 184.29 & -20.9 & 0.0073 \\
\hline Thiamine $(\mathrm{mg} / 4184 \mathrm{~kJ})$ & 3.8 & 8.0 & 3.5 & 8.9 & -0.3 & 0.43 & -11.9 & 0.0003 \\
\hline Riboflavin (mg/4184 kJ) & $3 \cdot 3$ & $6 \cdot 0$ & $3 \cdot 1$ & 5.9 & -0.2 & 0.38 & 2.5 & 0.6570 \\
\hline Niacin $(\mathrm{mg} / 4184 \mathrm{~kJ})$ & $26 \cdot 2$ & $60 \cdot 9$ & $26 \cdot 5$ & $80 \cdot 9$ & 0.3 & $2 \cdot 60$ & $-5 \cdot 3$ & 0.2664 \\
\hline Pantothenic acid (mg/4184 kJ) & $6 \cdot 2$ & $7 \cdot 4$ & $5 \cdot 7$ & $7 \cdot 1$ & -0.5 & 0.44 & -11.5 & 0.0073 \\
\hline Pyridoxine $(\mathrm{mg} / 4184 \mathrm{~kJ})$ & 4.8 & $10 \cdot 1$ & $4 \cdot 7$ & $9 \cdot 7$ & -0.1 & 0.84 & -5.4 & 0.3742 \\
\hline Cyanocobalamin ( $\mu \mathrm{g} / 4184 \mathrm{~kJ})$ & 18.5 & $72 \cdot 4$ & $18 \cdot 0$ & $50 \cdot 7$ & -0.5 & 5.05 & $-11 \cdot 8$ & 0.0748 \\
\hline Vitamin C $(\mathrm{mg} / 4184 \mathrm{~kJ})$ & 396.9 & $511 \cdot 0$ & $380 \cdot 6$ & $463 \cdot 2$ & $-16 \cdot 3$ & 29.08 & -9.6 & 0.1193 \\
\hline Cholecalciferol (mg/4184 kJ) & 8.9 & $6 \cdot 2$ & 8.5 & 5.9 & -0.4 & 0.34 & $-8 \cdot 1$ & 0.0748 \\
\hline Folic acid $(\mu \mathrm{g} / 4184 \mathrm{~kJ})$ & 252.9 & 133.5 & $229 \cdot 2$ & $116 \cdot 4$ & $-23 \cdot 7^{\star}$ & 9.23 & $-8 \cdot 0$ & 0.0140 \\
\hline$\alpha$-Tocopherol (mg/4184 kJ) & $59 \cdot 4$ & 83.5 & $60 \cdot 1$ & $77 \cdot 1$ & 0.8 & 4.68 & $65 \cdot 8$ & 0.0003 \\
\hline
\end{tabular}

${ }^{\star} P<0.05,{ }^{* * \star} P<0.001,{ }^{* * \star *} P<0.0001$ ( $t$ test).

†For details of subjects, diets and procedures, see Table 1 and p. 534.

$\ddagger$ Binomial sign test used to test the null hypothesis that the median $=0$.

$\S$ Percentage differences for ratios not calculated.

(Lovejoy et al. 2002). In addition, when subjects crossed over to the almond-supplemented diet, the protein intake pattern changed from animal to plant sources of protein, which is a strategy recommended by Shikany \& White (2000) to reduce saturated fat intake. This observation suggests that the protein content in almonds possibly displaced animal sources of protein in the almond-supplemented diet.

Although the average $\mathrm{Na}$ intake during the almond-supplemented diet period was greater than the recommendation of $\leq 2400 \mathrm{mg}$, it was a significant reduction from the subjects' habitual diets. Observed intake levels for $\mathrm{Ca}, \mathrm{Mg}$, folic acid and vitamin $\mathrm{D}$ in the almond-supplemented diet period were within the dietary recommendation for the prevention of chronic diseases or the current dietary reference intake (Trumbo et al. 2001).

There were no significant changes between the two diets for vitamin $\mathrm{C}$, and most of the B-group vitamins. The intake of these nutrients during the almond-supplemented diet period was within the dietary reference intake. In spite of the decrease in the intake of Se $(13 \%)$ and folic acid $(8 \%)$ from the habitual to the almond-supplemented diet, Se and folic acid in the almond-supplemented diet exceeded the dietary reference intake.

There is a superficially anomalous result (see Table 3): the mean change in $\alpha$-tocopherol intake between the two diets was only $0.8 \mathrm{mg} / 4184 \mathrm{~kJ}$, but this represents on average a $66 \%$ change. This is because the greatest increases were in those subjects who had a lower habitual intake of $\alpha$-tocopherol (the denominator), and thus these subjects contributed greater values to the average percentage change variable. Indeed, many of those subjects with the greatest habitual intakes (the supplementers) had a modest decrease in $\alpha$-tocopherol intake on the almondsupplemented diet due to decreased supplementation. Interestingly this pattern of reduced supplementation on the almond-supplemented diet was also noted for $\mathrm{Ca}$, vitamin $\mathrm{C}, \mathrm{Se}$ and $\mathrm{Zn}$. It seems possible that subjects concerned with nutrition and supplementation viewed the almonds as healthy and felt less need to supplement.

Some results in Table 3 (e.g. $\alpha$-tocopherol) may appear non-intuitive in that the median percentage difference differs markedly from mean $(\mathrm{a}-\mathrm{h}) /$ mean $(\mathrm{h})$ (where $\mathrm{h}$ is the mean intake from the habitual diet and a is the mean intake from the almond-supplemented diet). This is because even the mean rather than the median $(\mathrm{a}-\mathrm{h} / \mathrm{h})$ that we used is not equal to mean $(a-h) /$ mean $(h)$ in general. This is true especially when the denominator $(\mathrm{h})$ has a higher variance and when there is a correlation between the numerator $(\mathrm{a}-\mathrm{h})$ and the denominator. In the case under consideration the correlation between habitual intake (h) and change in intake $(\mathrm{a}-\mathrm{h})$ is $-0.40(P=0.0002)$.

During the intervention phase of our present study, subjects incorporated an average of $52 \mathrm{~g}$ almonds to their 
Table 4. Displacement of selected nutrients after 6-months supplementation with almonds* (Mean values for seven $24 \mathrm{~h}$ recalls for each diet period)

\begin{tabular}{|c|c|c|c|c|c|c|}
\hline & \multicolumn{2}{|c|}{ Dietary intake } & \multirow{3}{*}{$\frac{\text { Almond supplement } \dagger}{S}$} & \multicolumn{3}{|c|}{ Nutrient displacement } \\
\hline & \multirow{2}{*}{$\frac{\text { Habitual diet }}{\mathrm{H}}$} & \multirow{2}{*}{$\frac{\text { Almond diet }}{A}$} & & \multirow{2}{*}{$\frac{\text { Absolute (D) }}{\mathrm{S}+\mathrm{H}-\mathrm{A}}$} & \multicolumn{2}{|c|}{$\% \ddagger$} \\
\hline & & & & & $\mathrm{D} / \mathrm{S} \times 100$ & SEM \\
\hline Total food weight $(\mathrm{g} / \mathrm{d})$ & $3204 \cdot 2$ & 3074.9 & 51.9 & $181 \cdot 1$ & 329.2 & 113.0 \\
\hline Total energy $(\mathrm{kJ} / \mathrm{d})$ & $8528 \cdot 6$ & $9116 \cdot 9$ & $1286 \cdot 2$ & 697.9 & 54.4 & 17.9 \\
\hline Total protein $(\mathrm{kJ} / \mathrm{d})$ & 1243.0 & $1362 \cdot 3$ & $190 \cdot 0$ & $70 \cdot 7$ & $34 \cdot 2$ & $20 \cdot 4$ \\
\hline Vegetable protein $(\mathrm{kJ} / \mathrm{d})$ & $517 \cdot 0$ & $666 \cdot 2$ & $190 \cdot 0$ & 40.9 & $16 \cdot 4$ & $10 \cdot 7$ \\
\hline Total fat $(\mathrm{kJ} / \mathrm{d})$ & $2751 \cdot 3$ & $3501 \cdot 8$ & 1021.5 & 271.0 & $25 \cdot 9$ & 9.9 \\
\hline Total carbohydrate $(\mathrm{kJ} / \mathrm{d})$ & $4666 \cdot 8$ & 4443.4 & $168 \cdot 6$ & 392.0 & $245 \cdot 7$ & 73.9 \\
\hline Total dietary fibre $(\mathrm{g} / \mathrm{d})$ & $22 \cdot 2$ & $26 \cdot 5$ & $6 \cdot 1$ & 1.8 & 29.4 & 11.0 \\
\hline Sugars $(g / d)$ & $126 \cdot 4$ & $116 \cdot 6$ & 2.5 & $12 \cdot 4$ & $626 \cdot 0$ & $216 \cdot 7$ \\
\hline Water $(\mathrm{g} / \mathrm{d}) \S$ & 2757.4 & $2614 \cdot 1$ & $1 \cdot 7$ & $145 \cdot 1$ & $7691 \cdot 8$ & 3079.9 \\
\hline SFA $(\mathrm{kJ} / \mathrm{d})$ & 902.5 & 901.5 & $78 \cdot 3$ & 79.3 & 97.5 & $47 \cdot 8$ \\
\hline MUFA $(\mathrm{kJ} / \mathrm{d})$ & $1007 \cdot 1$ & $1554 \cdot 3$ & $650 \cdot 2$ & $102 \cdot 9$ & $16 \cdot 3$ & 6.4 \\
\hline PUFA (kJ/d) & 637.0 & $811 \cdot 1$ & $245 \cdot 0$ & $70 \cdot 8$ & $26 \cdot 3$ & $10 \cdot 5$ \\
\hline $16: 0(\mathrm{~kJ} / \mathrm{d})$ & 479.6 & $500 \cdot 3$ & 64.5 & $43 \cdot 8$ & $69 \cdot 0$ & $27 \cdot 8$ \\
\hline $18: 0(\mathrm{~kJ} / \mathrm{d})$ & $229 \cdot 2$ & $222 \cdot 9$ & $13 \cdot 8$ & $20 \cdot 1$ & 144.3 & $79 \cdot 3$ \\
\hline $16: 1 n-7(\mathrm{~kJ} / \mathrm{d})$ & 41.1 & $43 \cdot 6$ & 4.8 & $2 \cdot 3$ & 48.7 & 41.7 \\
\hline $18: 1 n-9(\mathrm{~kJ} / \mathrm{d})$ & 947.0 & $1492 \cdot 9$ & 645.4 & 99.4 & $15 \cdot 9$ & $6 \cdot 1$ \\
\hline $18: 2 n-6(\mathrm{~kJ} / \mathrm{d})$ & $564 \cdot 8$ & $744 \cdot 2$ & $245 \cdot 0$ & 65.6 & 24.7 & 9.4 \\
\hline $\mathrm{Ca}(\mathrm{mg} / \mathrm{d})$ & 1138.9 & $1162 \cdot 6$ & $135 \cdot 6$ & 111.9 & 89.3 & 32.9 \\
\hline $\mathrm{Fe}(\mathrm{mg} / \mathrm{d})$ & $26 \cdot 2$ & $26 \cdot 6$ & $2 \cdot 3$ & $2 \cdot 0$ & 91.8 & $76 \cdot 6$ \\
\hline $\mathrm{Mg}(\mathrm{mg} / \mathrm{d})$ & $396 \cdot 1$ & $510 \cdot 8$ & 147.0 & $32 \cdot 3$ & 21.6 & 9.2 \\
\hline$P(\mathrm{mg} / \mathrm{d})$ & $1338 \cdot 1$ & 1473.9 & 251.8 & $116 \cdot 0$ & $43 \cdot 3$ & $15 \cdot 5$ \\
\hline $\mathrm{K}(\mathrm{mg} / \mathrm{d})$ & $3044 \cdot 8$ & 3191.4 & 384.8 & 238.2 & 63.6 & 23.7 \\
\hline $\mathrm{Zn}(\mathrm{mg} / \mathrm{d})$ & 17.4 & 18.4 & 1.8 & 0.9 & $24 \cdot 1$ & $68 \cdot 3$ \\
\hline $\mathrm{Cu}(\mathrm{mg} / \mathrm{d})$ & 2.4 & 3.8 & 0.6 & -0.8 & $-128 \cdot 8$ & $144 \cdot 7$ \\
\hline $\operatorname{Se}(\mu \mathrm{g} / \mathrm{d})$ & $132 \cdot 5$ & $121 \cdot 3$ & 1.5 & $12 \cdot 7$ & $1010 \cdot 3$ & 464.4 \\
\hline Thiamine (mg/d) & 7.5 & 7.4 & 0.1 & 0.2 & -13.1 & $1077 \cdot 1$ \\
\hline Riboflavin (mg/d) & $6 \cdot 0$ & $6 \cdot 0$ & 0.4 & 0.4 & $135 \cdot 3$ & $172 \cdot 2$ \\
\hline $\operatorname{Niacin}(\mathrm{mg} / \mathrm{d})$ & 43.4 & 47.5 & $2 \cdot 0$ & $-2 \cdot 1$ & -94.9 & 304.9 \\
\hline Pantothenic acid (mg/d) & 11.9 & 11.4 & 0.1 & 0.7 & $531 \cdot 1$ & 534.8 \\
\hline Pyridoxine $(\mathrm{mg} / \mathrm{d})$ & 8.7 & 8.4 & 0.1 & 0.4 & 668.5 & $2260 \cdot 6$ \\
\hline Folic acid $(\mu \mathrm{g} / \mathrm{d})$ & $499 \cdot 3$ & 484.0 & $16 \cdot 6$ & 31.9 & $180 \cdot 1$ & $116 \cdot 2$ \\
\hline$\alpha$-Tocopherol (mg/d) & $107 \cdot 7$ & $117 \cdot 0$ & 13.5 & 4.2 & 51.5 & $60 \cdot 1$ \\
\hline$\beta$-Tocopherol (mg/d) & 0.4 & 0.6 & 0.2 & 0.0 & 11.3 & $10 \cdot 0$ \\
\hline$\gamma$-Tocopherol (mg/d) & $15 \cdot 2$ & 14.4 & 0.5 & 1.3 & 288.9 & 163.6 \\
\hline$\delta$-Tocopherol (mg/d) & $2 \cdot \overline{7}$ & $2 \cdot 8$ & 0.1 & 0.1 & 79.8 & $216 \cdot 2$ \\
\hline
\end{tabular}

${ }^{*}$ For details of subjects, diets and procedures, see Table 1 and p. 534.

t Almond supplement is the net difference in almond intake between the habitual and almond diets.

$\ddagger$ Mean of percentage differences.

$\S$ Including all fluids.

habitual diet per $d$. If the almond supplement was simply added to the habitual diet, one would expect the total weight of the almond-supplemented diet to increase by $52 \mathrm{~g}$, fat by $1022 \mathrm{~kJ}$ and energy by $1286 \mathrm{~kJ}$. This is not what occurred. The total weight of the almond-supplemented diet dropped by about $130 \mathrm{~g}$, fat increased by only $751 \mathrm{~kJ}$ and energy increased by $588 \mathrm{~kJ}$. In a previous publication, the authors reported on average no statistically significant changes in energy expenditure due to physical activity, resting or fasting, morning energy expenditure or RQ between the habitual and the almond-supplemented diet (Fraser et al. 2002). In that study, we also reported a small and non-significant weight gain $(0.4 \mathrm{~kg})$ over 6 months, but of course no information about future gains or losses. These findings suggest not only that the subjects' diets were more energy dense during the almond-supplemented diet $(2.96 \mathrm{~kJ} / \mathrm{g})$ compared with the habitual diet $(2 \cdot 66 \mathrm{~kJ} / \mathrm{g})$, but also they provide strong evidence that nutrient displacement occurred despite the possibility of a small weight gain.
Our calculations show that energy in the almondsupplemented diet was partially displaced by almonds. Other investigators observed similar findings during freefeeding with peanuts (Alper \& Mattes, 2002). Displacement estimates show that almonds displaced macronutrients in the following order (from smallest to greatest percentage displacement): fat $<$ protein $<$ carbohydrate. Interestingly, this displacement pattern is similar to that found in shortterm satiety studies in which fat was shown to be slightly or much less satiating than carbohydrate (Foltin et al. 1992; Green et al. 1994; Rolls et al. 1994), which means that more fat was eaten.

The displacement pattern of dietary fatty acids (MUFA $<$ PUFA $<$ SFA, and 18:1<18:2<18:3), combined with the observation that animal protein intake was reduced in the almond-supplemented diet period, suggests that almonds may have induced a change in the diet that led to a retention of its monounsaturated fats while displacing other fats by reducing the intake of foods high in saturated fats, such as meats, cheeses and 
Table 5. Comparison of the almond-supplemented diet with dietary recommendations *

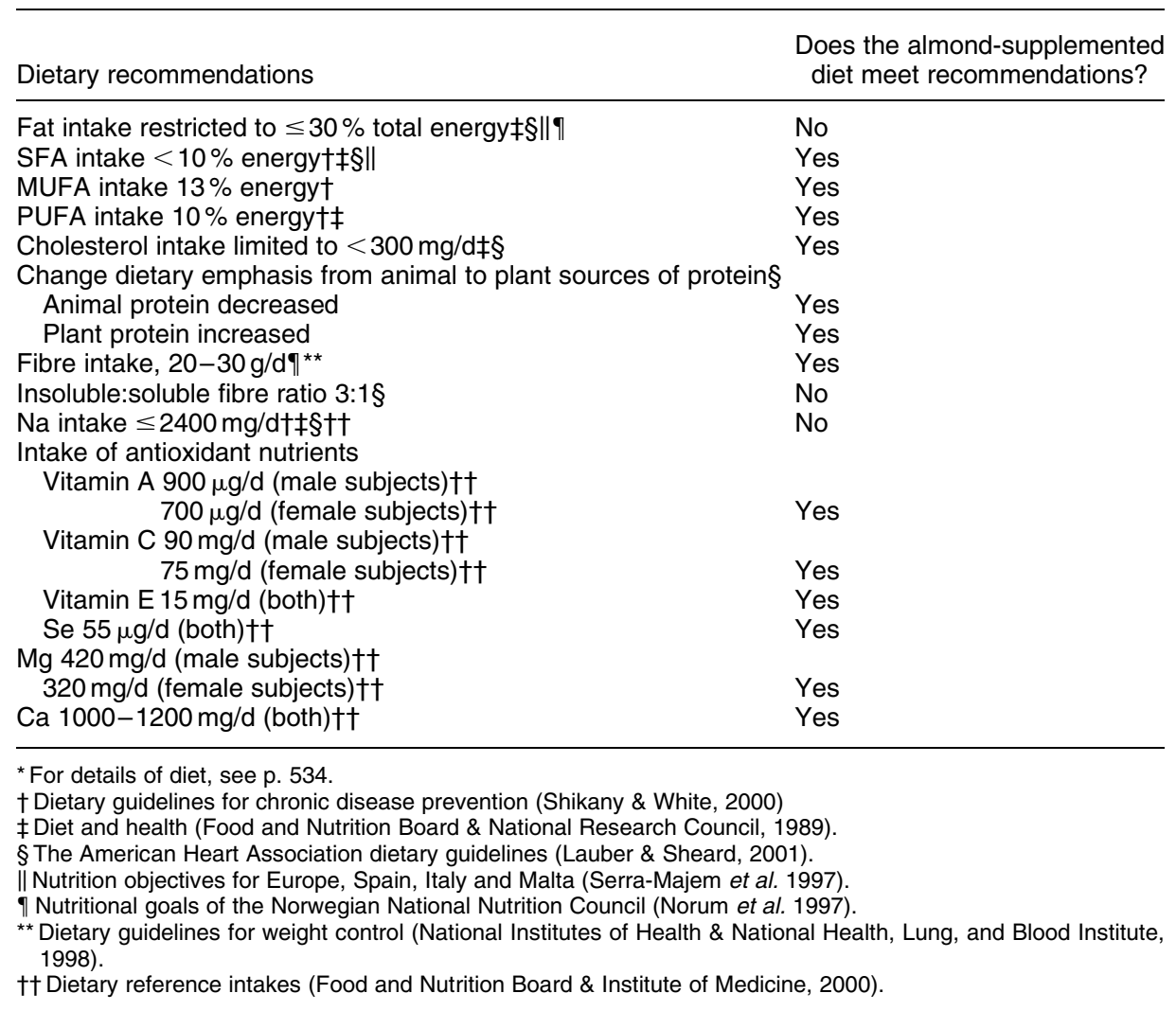

other dairy products. Since the carbohydrate content of almonds is small, it is perhaps not surprising that all of it could be displaced. The estimated carbohydrate displacement of $246 \%$ suggests that an additional $146 \%$ carbohydrate from other sources was eliminated. Given that the intake of fibre was greater and sugar was lower in the almond-supplemented diet period, it is possible that almonds induced a specific displacement pattern that reduced the intake of sugar-rich foods, or increased the intake of complex carbohydrates such as fruits and vegetables in the supplemented diet.

To summarize, when almonds were incorporated into the habitual self-selected diets of healthy subjects, total energy, total protein, total fat, SFA, MUFA, PUFA, total fibre, $\mathrm{Ca}, \mathrm{Fe}, \mathrm{Mg}, \mathrm{P}, \mathrm{K}, \mathrm{Zn}$ and $\alpha$-tocopherol were partially displaced in the supplemented diet. Total food weight, carbohydrate, sugars, stearic acid, Se, riboflavin, pantothenic acid and folic acid were more than fully displaced, and the almond-supplemented diet contained less of these nutrients. Nutrient displacement estimates in the present study may be a potential indicator of the degree to which a particular nutrient from almonds is metabolized. More research is needed to evaluate the food displacement and eating patterns of individuals after supplementing their habitual diets with nuts. Results from such an investigation may reveal behavioural eating patterns that may be useful in dietary interventions and in teaching the larger population how to incorporate nuts into their habitual diets, as well as generate other hypotheses regarding the metabolism of nuts.

\section{Acknowledgements}

The authors are grateful to the California Almond Board for a grant to support this work, and to Dr Ingrid Hoffmann for her critical comments on a previous draft of this manuscript.

\section{References}

Albert CM, Gaziano JM, Willett WC \& Manson JE (2002) Nut consumption and decreased risk of sudden cardiac death in the Physicians' Health Study. Arch Intern Med 162, $1382-1387$.

Almario RU, Vonghavaravat V, Wong R \& Kasim-Karakas SE (2001) Effects of walnut consumption on plasma fatty acids and lipoproteins in combined hyperlipidemia. Am J Clin Nutr 74, 72-79.

Alper CM \& Mattes RD (2002) Effects of chronic peanut consumption on energy balance and hedonics. Int $J$ Obes Relat Metab Disord 26, 1129-1137.

Appel LJ, Moore TJ, Obarzanek E, et al. (1997) A clinical trial of the effects of dietary patterns on blood pressure. DASH Collaborative Research Group. $N$ Engl J Med 336, 1117-1124.

Food and Nutrition Board, National Research Council (1989) Diet and Health: Implications for Reducing Chronic Disease Risk. Washington, DC: National Academy Press.

Curb JD, Wergowske G, Dobbs JC, Abbott RD \& Huang B (2000) Serum lipid effects of a high-monounsaturated fat diet based on macadamia nuts. Arch Intern Med 160, 1154-1158.

Foltin RW, Rolls BJ, Moran TH, Kelly TH, McNelis AL \& Fischman MW (1992) Caloric, but not macronutrient, 
compensation by humans for required-eating occasions with meals and snack varying in fat and carbohydrate. Am J Clin Nutr 55, 331-342, (erratum in Am J Clin Nutr (1992) 56, 954).

Food and Nutrition Board, Institute of Medicine (2000) Dietary Reference Intakes for Vitamin C, Vitamin E, Selenium, and Carotenoids. A Report of the Panel on Dietary Antioxidants and Related Compounds. Washington, DC: National Academy Press.

Fraser GE, Bennett HW, Jaceldo KB \& Sabate J (2002) Effect on body weight of a free 76 kilojoule (320 calorie) daily supplement of almonds for six months. J Am Coll Nutr 21, 275-283, (erratum in $J$ Am Coll Nutr (2002) 21, 363).

Fraser GE, Sabate J, Beeson WL \& Strahan TM (1992) A possible protective effect of nut consumption on risk of coronary heart disease. The Adventist Health Study. Arch Intern Med 152, 1416-1424.

Fung TT, Rimm EB, Spiegelman D, Rifai N, Tofler GH, Willett WC \& Hu FB (2001) Association between dietary patterns and plasma biomarkers of obesity and cardiovascular disease risk. Am J Clin Nutr 73, 61-67.

Green SM, Burley VJ \& Blundell JE (1994) Effect of fat- and sucrose-containing foods on the size of eating episodes and energy intake in lean males: potential for causing overconsumption. Eur J Clin Nutr 48, 547-555.

Haddad E (2001) Vegetarian diets and dietary guidelines for chronic disease prevention: how meatless diets conform to current recommendations for healthy eating. In Vegetarian Nutrition, pp. 551 [J Sabate, editor]. Boca Raton, FL: CRC Press.

Hu FB, Stampfer MJ, Manson JE, Rimm EB, Colditz GA, Rosner BA, Speizer FE, Hennekens CH \& Willett WC (1998) Frequent nut consumption and risk of coronary heart disease in women: prospective cohort study. Br Med J 317, 1341-1345.

Jenkins DJ, Kendall CW, Marchie A, et al. (2003) The effect of combining plant sterols, soy protein, viscous fibers, and almonds in treating hypercholesterolemia. Metabolism 52, 1478-1483.

Jiang R, Manson JE, Stampfer MJ, Liu S, Willett WC \& Hu FB (2002) Nut and peanut butter consumption and risk of type 2 diabetes in women. $J$ Am Med Assoc 288, 2554-2560.

Kris-Etherton PM, Yu-Poth S, Sabate J, Ratcliffe HE, Zhao G \& Etherton TD (1999) Nuts and their bioactive constituents: effects on serum lipids and other factors that affect disease risk. Am J Clin Nutr 70, 504S-511S.

Lauber RP \& Sheard NF (2001) The American Heart Association Dietary Guidelines for 2000: a summary report. Nutr Rev 59, 298-306.

Lovejoy JC, Most MM, Lefevre M, Greenway FL \& Rood JC (2002) Effect of diets enriched in almonds on insulin action and serum lipids in adults with normal glucose tolerance or type 2 diabetes. Am J Clin Nutr 76, 1000-1006.

McManus K, Antinoro L \& Sacks F (2001) A randomized controlled trial of a moderate-fat, low-energy diet compared with a low fat, low-energy diet for weight loss in overweight adults. Int J Obes Relat Metab Disord 25, 1503-1511.

Must A, Dallal GE \& Dietz WH (1991) Reference data for obesity: 85th and 95th percentiles of body mass index (wt/ $\mathrm{ht}^{2}$ ) and triceps skinfold thickness. Am J Clin Nutr 53, 839-846, (erratum in Am J Clin Nutr (1991) 54, 773).

National Institutes of Health \& National Health, Lung, and Blood Institute (1998) Clinical Guidelines on the Identification, Evaluation, and Treatment of Overweight and Obesity in Adults. The Evidence Report NIH Publication No. 98-4083. Bethesda, MD: US Department of Health and Human Services, NIH, NHLBI.

Norum KR, Johansson L, Botten G, Bjorneboe GE \& Oshaug A (1997) Nutrition and food policy in Norway: effects on reduction of coronary heart disease. Nutr Rev 55, S32-S39.

Prineas RJ, Kushi LH, Folsom AR, Bostick RM \& Wu Y (1993) Walnuts and serum lipids. $N$ Engl $J$ Med 329, 359, discussion 359-360.

Rajaram S, Burke K, Connell B, Myint T \& Sabate J (2001) A monounsaturated fatty acid-rich pecan-enriched diet favorably alters the serum lipid profile of healthy men and women. J Nutr 131, 2275-2279.

Rolls BJ, Kim-Harris S, Fischman MW, Foltin RW, Moran TH \& Stoner SA (1994) Satiety after preloads with different amounts of fat and carbohydrate: implications for obesity. Am J Clin Nutr 60, 476-487.

Sabate J \& Fraser G (1993) The probable role of nuts in preventing coronary heart disease. Primary Cardiol 19, 65-72.

Sabate J, Haddad E, Tanzman JS, Jambazian P \& Rajaram S (2003) Serum lipid response to the graduated enrichment of a step I diet with almonds: a randomized feeding trial. Am J Clin Nutr 77, 1379-1384.

Sabate J, Radak T \& Brown J (2001) The role of nuts in cardiovascular disease prevention. In Handbook of Nutraceuticals and Functional Foods, pp. 477-495 [REC Wildman, editor]. Boca Raton, FL: CRC Press.

Schakel SF, Sievert YA \& Buzzard IM (1988) Sources of data for developing and maintaining a nutrient database. J Am Diet Assoc 88, 1268-1271.

Serra-Majem L, Ferro-Luzzi A, Bellizzi M \& Salleras L (1997) Nutrition policies in Mediterranean Europe. Nutr Rev 55, S42-S57.

Sheskin DJ (2000) Handbook of Parametric and Nonparametric Statistical Procedures, pp. 185-188. Boca Raton, FL: Chapman, Hall/CRC.

Shikany JM \& White GL Jr (2000) Dietary guidelines for chronic disease prevention. South Med J 93, 1138-1151.

Trumbo P, Yates AA, Schlicker S \& Poos M (2001) Dietary reference intakes: vitamin A, vitamin $\mathrm{K}$, arsenic, boron, chromium, copper, iodine, iron, manganese, molybdenum, nickel, silicon, vanadium, and zinc. J Am Diet Assoc 101, 294-301.

Wien MA, Sabate JM, Ikle DN, Cole SE \& Kandeel FR (2003) Almonds vs complex carbohydrates in a weight reduction program. Int J Obes Relat Metab Disord 27, 1365-1372.

World Health Organization (1990) Diet, Nutrition, and the Prevention of Chronic Diseases. Report of a WHO Study Group. World Health Organization Technical Reports Series no. 797. Geneva: WHO. 